\title{
Cuando los lugares dirimidos hablan: precariedad en la obra de Carmen Berenguer, Gabriela Cabezón Cámara, Diamela Eltit y Samanta Schweblin*
}

\author{
When Cancelled Spaces Speak: Precariousness in the Work \\ of Carmen Berenguer, Gabriela Cabezón Cámara, \\ Diamela Eltit and Samanta Schweblin
}

\section{Áurea María Sotomayor Milettı \\ Universidad de Pittsburgh Pittsburgh, Estados Unidos}

DOI: https://doi.org/10.32719/13900102.2020.48.4

Fecha de recepción: 30 de enero de 2020 Fecha de aceptación: 6 de marzo de 2020

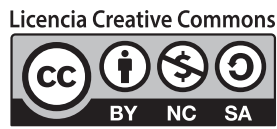

* Este texto fue leído por la autora en LASA Cono Sur (Montevideo), entre el 19 y el 22 de julio de 2017. 


\section{RESUMEN}

El artículo reflexiona alrededor de un corpus narrativo del Cono Sur desde una mirada que articula lugares, habla, comunidad, réplica y documento. Los textos que constituyen el corpus de "ficción documental", objeto de estudio, son: Naciste pintada (1999), de Carmen Berenguer; un segmento de un expediente judicial, Puño y letra (2005), de Diamela Eltit; una acción política devenida acción de arte local que se exporta a Venecia, El romance de la negra rubia (2014), de Gabriela Cabezón Cámara, y un territorio contaminado habitado además por el delirio agónico de quien lo narra, Distancia de rescate (2014), de Samanta Schweblin. Las narrativas estudiadas proponen otro modelo donde si bien la violencia es documentada, esta se registra de otra forma: la pregunta respecto al devenir violento se centra en las hablas que la distribuyen, permaneciendo abierto el énfasis en el rango mismo del decir.

Palabras Clave: ficción-documental, Cono Sur, espacio, género, documento, violencia, mujeres, escritura, cuerpo, resistencia.

\section{ABSTRACT}

The article reflects on a narrative corpus borne out of the Southern Cone from a viewpoint that articulates places, speech, community, response, and documentation. The texts that constitute the corpus of "documentary fiction", that are the object of this study, are Naciste pintada (1999), by Carmen Berenguer; a segment of a judicial file, Puño y letra (2005), by Diamela Eltit; a political action turned into a local art performance that is exported to Venice, El romance de la negra rubia (2014), by Gabriela Cabezón Cámara and a contaminated territory inhabited by the agonizing delirium of the narrator, Distancia de rescate (2014), by Samanta Schweblin. The studied narratives propose another model in which, although violence is documented, it is recorded in a different way, and questions concerning violent becomings are centered on the speeches that distribute them, emphasizing the range of speech itself which remains open.

KEYWORDS: documentary-fiction, Southern Cone, space, gender, documentation, violence, women, writing, body, resistance.

¿En qué momento de la historia es apropiado indignarse?

Samanta Schweblin

HABría Que enUmerarlos para hacerlos explícitos: lugares, habla, comunidad, réplica, documentar. Son términos que activan el imaginario del sitio desde donde se actúa, espacio siempre dirimido, porque en ellos no se coagula el tiempo; espacios tránsfugas desde donde se activan tácticas y no estrategias. Las tácticas las ejercen aquellos que carecen de territorio fijo y las estrategias las imponen quienes consolidan su poder en un espacio particular. Documentar, por su lado, posee una fuerte carga expresiva, por razón de la realidad que evoca, pues incluye el acopio de evidencia mate- 
rial con un objetivo específico. El acto de documentar opera, entre otros, para ordenar las cronologías, que en este ensayo remiten a varias ficciones escritas de los setenta hasta hoy día en el Cono Sur, casi todos ellos textos escritos al filo del siglo XXI. La acción de documentar incluye la ambición de archivar el tiempo en el que se formulan comunidades imaginarias, en este caso, plenamente fictivas, comprometidas con su continua reconstrucción. El método adoptado en estas ficciones documentales consiste en recopilar imágenes y hablas, y esparcirlas a lo largo de los textos para dar fe de su existencia. En esta lectura quiero recalcar las hablas, que ostentan tres modos escriturales recurrentes: la cita, la parodia y la ambigüedad. Su radio de acción o su espacio es una casa dividida en tres secciones (Naciste pintada, 1999, de Carmen Berenguer), un segmento de un expediente judicial (Puño y letra, 2005, de Diamela Eltit), una acción política devenida acción de arte local exportado a Venecia (El romance de la negra rubia, 2014, de Gabriela Cabezón Cámara) y un territorio contaminado, habitado por el delirio agónico de quien lo narra (Distancia de rescate, 2014, de Samanta Schweblin).

Como el lugar se fragua materialmente a partir de la interacción entre el territorio y sus habitantes, ${ }^{1}$ estos que habitan las protagonistas de dichos textos son lugares tránsfugas y en principio precarios porque son espacios comunes, sin propietario, o tóxicos, donde quienes allí viven son desahuciados, maltratados y marginados. Basta con enumerarlos para intuirlos: el prostíbulo y la cárcel, la sala de un tribunal, un lugar donde viven okupas y un territorio contaminado de químicos agropecuarios. Son, además, precarios porque sus habitantes están "fuera de lugar" y sus protagonistas son mujeres. Véase que si el término "anaforismo" (Cresswell) se atribuye, en principio, a entes "descolocados" respecto a los espacios normativos, en este caso, por razón de que el lugar se define a partir de una mutua o recíproca con-figuración, tanto este como su habitante se halla en estado precario en términos de su estabilidad y seguridad físicas. El cuerpo es el gran comprometido en estos sitios. Como bisagra de engranaje social, es el cuerpo femenino mismo, en su habitar, el que se inmola. Ya Doreen Massey y Luce Irigaray han analizado la estrecha relación existente

1. Lugares o "localities" son definidos por Massey (1994) como "constructions out of the intersections and interactions of concrete social relations and social processes in a situation of co-presence" (139). 
entre espacio y género, y la amenaza que representa el cuestionamiento del orden patriarcal y falocéntrico. ${ }^{2}$ La escritora chilena Diamela Eltit, por ejemplo, emplaza a la masculina institución judicial misma al citar en su Puño y letra un fragmento del pliego judicial. Extrae un documento que de otra forma quedaría ocultado por la burocracia jurídica en un archivo y expone algunas de sus partes: un testimonio, que devela los procedimientos y herramientas, el habla aparentemente neutral del montaje judicial. Allí, la violencia habla por sí misma, y su discurso —el del pliego judicial que emplaza y cita- es neutral, excepto cuando cita a los testigos.

En el texto de Carmen Berenguer se trata de trabajar la fecunda metáfora de la casa al voltear la categoría bachelardiana de la residencia convencional con el típico ático y sótano siniestros, y proponer una casa de citas o una casa penal al estipular tres fórmulas habitables: la casa de la poesía, el prostíbulo y la cárcel, lugares donde las protagonistas, todas ellas mujeres cercadas por la violencia, se arman de un sistema de afirmaciones mediante el habla, y estremecen el orden social que las confina a los espacios prostibularios o carcelarios. Así ocupan y emplazan también el espacio de la opinión pública desde su lengua al navegar hacia el texto literario. La prensa, el Estado, la ciudad letrada misma, califica de mujer loca — como diría la Mistral en su momento- a quien habla, pero ella insiste en su réplica. El lenguaje de odio con que es interpelada es devuelto en forma de presagio, amonestación, descripción o conjuro, desde la casa de la poesía, y como testimonio desde la casa prostibularia y la cárcel. La crónica periodística estimula a buscar los diversos ángulos del lupanar a partir de los testimonios contradictorios de sus habitantes, mientras que los relatos carcelarios en primera persona definen el lugar de la cárcel y el rédito que cobra en el espíritu y los cuerpos. Las mujeres se redimen a partir de una particular habla de la sobrevivencia. Aun allí hallan estas mujeres lugares desde donde re-construir el mundo y el lenguaje. Uno de los mejores ejemplos es el ofrecido sobre Brenda al mirarse en el espejo de las aguas neobarrosas conosureñas: "No olvidemos que ella no usa espejo. Brenda se mira en los charcos. Allí vio su primera imagen. [...] Cuando hablan de arte está ese espejo señalándome su estética. Tal charco latino platica y

2. D. Massey: "In certain cultural quarters, the mobility of women does indeed seem to pose a threat to a settled patriarchal order" (11). Me refiero principalmente a Speculum of the Other Woman y This Sex Which is Not One, de Luce Irigaray. 
murmura orfandad en su sabiduría. Ese charco hizo escuela en mi cabeza y pobló la incoherencia de sus calles" (Berenguer 66-7). Así, la totalidad de la obra de Berenguer puede leerse como un "cuerpo violentado por la flecha del verso", "cuerpo que se representa en estado de privación”, según Francine Massiello $(2016,32)$. Desde la violencia se ejercitan y ejecutan sus hablas y, como bien señala Cárcamo Huechante, “[e]n esta ruta barroco-urbana de la poesía de Berenguer también se establece una distancia respecto del exceso de literaturiedad y culto al autorreferencialismo de la escritura 'latinoamericana', y en su contraparte, Berenguer se descorre, como el rouge sobre el cuerpo femenino y travesti, sudado y sudaca, para dejarse permear por el callejeo urbano, popular y político de su persona poética" (77). Dentro del neobarroco mismo, el poeta Jaime Lizama describe el lenguaje de otro libro de Berenguer, A media asta, de forma tal que bien podría aplicarse a toda la poesía y poética berengueriana, como un habla mestiza que deja emerger lo soterrado y "una voluntad lúdica y lúbrica” $(2016,50)$.

Por su parte, en Romance de la negra rubia, Gabriela Cabezón Cámara se acomoda en "una poética de barra" (33) desde donde se describe una acción de arte en la forma estrófica de un neorromance popular en estilo barroco. El desfase formal existente entre la estrofa y la descripción de la performance que ocupa la trama del texto de Cabezón insinúa la presencia de un público masivo que la observa y a quien se dirige, reformulando críticamente, mediante el estilo desigual, la autoría y su "verdad", comprometiendo así el potencial político de dicha posición estética tornándolo paródico. Finalmente, en la obra de Schweblin se evoca la toxicidad letal en un distante territorio del sur a partir de un diálogo continuo de tres personajes sobre quienes se construye el suspenso y se sugiere el horror respecto al enigma de lo que ocurre. En tres de los casos, y parcialmente en uno, se trata de texturas eminentemente orales que se explayan sobre un territorio construido a partir del habla entre mujeres. Todas estatuyen de algún modo lo que es difícil verbalizar: la violencia, la mentira y el delirio. Lo determinante en estas narrativas es que todo ello se representa sin los trazos de victimación cónsonos a narrativas similares. Es decir, el modus operandi del proceso de "documentar", a saber, el uso de la cita en Eltit y Berenguer, o la distancia provista por la espectacularización crítica de la performance de La negra rubia, o el delirio dialógico en la novela de Schweblin pone en paréntesis el yo y sus valoraciones típicas en otros 
textos, y sobre todo, escabuye y aplaza, por así decirlo, el trance anunciado de una escena de sacrificio que la narración parecería presagiar. Desdramatizar el yo opera de diferentes maneras en el caso del texto de Berenguer, donde es la voz poética o la crónica periodística o el relato directo de las torturadas quienes ocupan el espacio fictivo. Decir esto como si se tratara de un testimonio despoja al texto del elemento de valoración implícito en el género novelístico convencional. Pero no hay dramatismo aquí ni tampoco expectativa morbosa respecto a los detalles de la tortura, como sí les ocurre a los cadáveres de 2666 de Roberto Bolaño. Al asumir la palabra, las protagonistas de estas novelas se despojan del lastre victimizador, pues hacerlo comporta un gesto afirmativo que empieza a construirlas como potenciadoras de su futuro. En tal sentido, la pregunta formulada por Jean Franco en Cruel Modernity, un libro que se ocupa de varios relatos de victimación femenina en América Latina en el contexto de la modernidad, viene a colación aquí respecto a la formación de subjetividades violentas correspondientes a ese período. Lo que quiero afirmar es que las narrativas de las que me ocupo estatuyen otro modelo, donde si bien se rinde cuenta de la violencia documentándola, esta se registra de otra forma, y la pregunta respecto al devenir violento se centra en las hablas que la distribuyen, permaneciendo abierto el énfasis en el rango mismo del decir.

Una relación somera de los textos podría ir orientando mi argumento. Comencemos por el territorio ocupado por una empresa tóxica en la novela de Schweblin. Dicho relato se moviliza a partir del intercambio dialógico entre una moribunda, Amanda, y un niño de unos nueve años, David, tratando de reconstruir el "origen" de los "gusanos" que los han envenenado. El horror que atraviesa el relato contado a tres voces y con numerosas interrupciones temporales es infundido por tres aspectos: a) el presagio del mal en la infancia y el papel desempeñado por la madre para evitarlo; b) la presencia ominosa de otro mal representado por los "gusanos" mediante un lenguaje incapaz de dar cuenta de la toxicidad ambiental, a menos que lo ilustre somáticamente ("dan picor”); y c) la presencia intermitente de una curandera que exige e impone un sacrificio para salvar el espíritu, consistente en despojar al niño de su cuerpo para hundirlo en la orfandad y el abandono. La pregunta sería: ¿cómo indemnizar del dolor a los que quedan? ¿Cómo reparar la violencia que experimenta el niño como víctima principal de esta intoxicación globalizadora? Lo que la novela expone es la orfandad, el despojo y la violencia en medio de la plaga de los glifo- 
satos y el agrocapitalismo global en un campo de soja transgénica. El “origen" de la violencia en este sentido no es la violencia transgénica impuesta sobre un territorio del capitalismo neoliberal, sino el sistema mismo que lo perpetúa. El que el relato o el interrogatorio o el intercambio comunicativo esté violentamente fracturado por las perspectivas desde las cuales se narra es índice del agujereamiento de una explicación única respecto a un tópico narrativo reiterado en la novela. He leído este texto en varias ocasiones y siempre me acosa una sensación que es también una inquietud: la dificultad de identificar a qué otorgarle primacía interpretativa cuando varios planos narrativos se solapan. Ciertamente, el texto de Schweblin apunta hacia esa equivalencia de las alternativas interpretativas. En ese sentido, me planteo si acaso no sea el texto relativo al paisaje tóxico, tanto como la violencia soterrada literalmente impuesta a las víctimas ignorantes que aceptan sin mayores indagaciones su destino, una alternativa justa de lectura. Por esa ruta entonces, la curandera (que me parece central al relato) no formaría parte de lo principal, sino como corolario de este plan sistémico de destrucciones sucesivas de la población, dado el caos ambiental imperante. ${ }^{3}$

La pobreza extrema hecha metáfora en una tierra donde no pasa nada, infértil y sin movimiento, da paso a la exposición del material humano desprovisto de deseo y el horizonte vital que allí habita. Ese "sin deseo" es el infierno mismo, y de ahí proviene el terror, narrado como si fuese una cotidianidad inofensiva, pero inapelable, letal. Como subraya la cita: "Ahora bien, ¿es posible discernir 'el punto exacto en el que nacen los gusanos"” (11). ¿ Es factible conocer el origen o la causa última? ¿Y qué son los gusanos? ¿En función de qué retornamos a esta metáfora que es expresión incierta en el lenguaje infantil? Para quien ve en los gusanos el efecto del operador tóxico, el fin del relato es la crítica de la toxicidad, lo cual es una posibilidad de lectura. Sin embargo, en otro momento de la narración Daniel dice: "el punto exacto está en un detalle, hay que ser observador" (14). ¿ ¿Se trata acaso del momento en que "la distancia de rescate" es posible, cuando el padre puede sustituir a la madre en su papel, y no lo hace? Entonces, ¿es el propósito de la narración dar cuenta del nuevo paisaje ambiental o del nuevo paisaje afectivo? Y si es así, ¿por

3. "Bajo tierra" y "La furia de las pestes", dos relatos incluidos en la colección de cuentos Pájaros en la boca (2015) dan cuenta de estos pueblos fronterizos y secos, paisajes que son resultado de dicha explotación ambiental. 
qué no decirlo más directamente? En una entrevista concedida por la autora a raíz de la publicación de la nouvelle, Schweblin descarta la literatura panfletaria y edificante, es decir, la dirigida a un fin que rebase lo literario. Pero acaso los titubeos y discrepancias entre lo que se debe o no debe contar entre Amanda y David sean un indicio de que no se trata del paisaje exterior, a saber, el nuevo paisaje construido por el agrocapital, ya no por las bananeras y el petróleo. Se trata de las alucinaciones, las trasposiciones de identidad, la falta del reconocimiento del otro causado por el extrañamiento, la fractura generacional donde padres e hijos pierden contacto: el caballo que se desploma al beber del riachuelo, el pájaro muerto, el niño transmigrado, en cierto sentido, también desaparecido.

En la casa verde la curandera es capaz de leer la energía de la gente, "pero esta gente además de esotérica es bastante sensata", dice Carla en su distancia deíctica ("esta") respecto a su lectura de la ceremonia del rescate. En otro momento Amanda le pregunta a Carla: “¿En qué momento de la historia es apropiado indignarse?” (28). Es decir, éticamente hablando, ¿se trata aquí de la justicia? El rescate no lo es, solo queda la distancia y la indignación ante una secuela de incidentes aparentemente injustos. La curandera produce un híbrido, otro tipo de "trasgénico". El secuestro y robo de niños durante la dictadura viene a colación, el quiebre de la línea genealógica, la derecha apropiándose de los niños de otros, el extrañamiento que produce el enemigo en la propia casa. Entonces, ¿̨es otro evento político el que se recuenta aquí? Vale la pena recordar esta aserción: "La trasmigración se llevaría el espíritu de David a un cuerpo sano, pero traería también un espíritu desconocido al cuerpo enfermo. Algo de cada uno quedaría en el otro, ya no sería lo mismo, y yo tenía que estar dispuesta a aceptar su nueva forma" (28; énfasis suplido).

Carla debía "asumir el compromiso" de ser responsable del cuerpo de David "pasara lo que pasara”. Cuando Amanda y Nina se intoxican, Amanda es incapaz de dar su consentimiento para que Nina, su hija, sea intervenida por la hechicera. Ese detalle legal torna ilícita la ceremonia transmigratoria. De otro lado, la soja recién cortada atraviesa el relato como un signo ominoso. La narradora juega con nuestras referencias fílmicas. Children of the corn transcurre en un pueblo rural donde los niños eventualmente asesinan a sus padres, mientras que en esta novela un niño intoxicado se convierte en un elemento extraño con potencialidades agresivas. Su genealogía se interrumpe, sus padres le temen, se invierte el eje de 
la autoridad y el niño deviene un monstruo para su madre (34). Otro filón del relato atañe a la relación con el otro que surge cuando Amanda ve por primera vez a la niña con frente monstruosa que renguea: "Está bien que Nina vea esto, pienso. Está bien que sepa que no todos nacemos iguales, que aprenda a no asustarse. Pero secretamente pienso que si esa fuera mi hija no sabría qué hacer" (42). La distancia entre un niño y el otro tiene potencialidades negativas ahora y lo que se subraya es la distancia respecto al otro, pese a que el comentario de Amanda aspira a ser políticamente correcto. ¿Es aceptable que sepa de su existencia (la de la diferencia), pero no que lo sea? Básicamente, lo que ocurre en el relato es esa trasposición, el registro y la constatación de que esa posición políticamente correcta se torna intrascendente en el momento en que se materializa la cercanía. La "realidad" descrita en esta nowvelle es un horror del que no se sale, y el aparente diálogo no lo es, sino un monólogo con lo imposible.

¿Qué emparenta este trabajo de Schweblin con El romance de la negra rubia de Cabezón Cámara? Quiero pensar que una fascinación con el lenguaje que, por un lado, asume un gesto de denuncia y, por el otro, se suma en la posibilidad de un 'nosotros' que erige "la voz de los sin voz". ¿Pero de qué nosotros se trata cuando se enfrenta un ejército que convalida la fuerza erga omnes de la propiedad vis a vis unos okupas y una mujer incinerada en medio de la histeria informática? Veamos el desencadenamiento de la acción una vez la policía emplaza a los okupas:

Al final de la contienda, entre los míos hubo cuatro caídos de caída reparable por los corchazos de caucho, dos caídos para siempre por un par de canas que no padecen el efecto cámara del mismo modo que sus compañeros y un patrullero laminado por el futón que había cortado breve pero contundente el aire de la avenida. $Y$ unos cuarenta detenidos, esos todos del lado de los míos. Después de llenar los camiones con los revoltosos, la policía procedió al desalojo y acordonó el edificio. Alrededor, aquellos de los míos que no estaban presos ni caídos comenzaron a improvisar un campamento, pero ya al grito de "itenemos tres muertos, tenemos tres muertos!". Cuando alguno vio en su celular que la prensa estaba titulando así: "Dos muertos y una mujer agonizando en un desalojo", se acordaron de los créditos y agradecieron: fue 'invalorable', le dijeron a las cámaras, la ayuda de la ONG. El Techo Propio, que envió cientos de metros de manteles de nylon de claro origen chino y de incierto periplo internacional: nadie sabía de dónde los había sacado la ONG. Tampoco había tiempo de preguntarse nada y mucho menos de inquirir sobre la procedencia de lo necesario (16). 
También el Estado se pronuncia en este texto, pero desde la proximidad representada por sus uniformes convertidos en atractivos textiles fluorescentes, y la informática que modifica o altera los "productos". De hecho, todo se maneja como mercancía, y lo que fue un acto azaroso por parte de "la artista de la basura" (la mujer se quema por hallarse drogada y embriagada), deviene un acto de resistencia cuyos réditos se insertan de forma bivalente, tanto por la vía del reclamo de territorio para los sin casa, como también insertándose en la narrativa de un turismo global, que incluye trasplantes de rostro u operaciones donde la identidad se diluye. El Romance de la negra rubia es un texto que apela ya desde un principio a unos tópicos críticos relativos a la performance, en boga actualmente. Entonces, no se interpela ni evoca paródicamente a un lector, sino a una línea crítica, y Cabezón Cámara se desplaza (no sé si conscientemente) en una especie de vaivén ambiguo, cuestionándola, para cerrar el círculo de los territorios legítimos y hegemónicos, uno propietario (el del territorio ocupado) y el otro crítico (el del performance combativo como nueva resistencia). ${ }^{4}$

Porque se trata de un mundo en rápida licuefacción, el emplazamiento al lector plantea otro problema ético. En este caso, y también en el otro, se recurre a nominar la acción como un sacrificio, ${ }^{5}$ esclareciéndolo en la "Coda", en caso de que quien lea no haya entendido bien. El "nuestro" y el "nosotros" es el eje en torno al cual giran los verdaderos sucesos:

Es bastante heterogénea la primera del plural, los nuestros no son nosotros y eso hay que tenerlo claro. No todo sacrificado genera una tradición, pero el martirio espontáneo siempre genera su primer muerto, como primer empujón o como fuerza motora de un efecto dómino que según de qué se trate dura una generación o puede durar centenios, aunque pensándolo bien, lleva un buen par de milenios. (73)

4. "Porque siempre quise escribir uno y ha de ser que soy una de esas personas que no pueden separar arte de vida y la vida me quedó así, medio barroca, retorcida, como una torre de Borromini, confusa, agujereada, pegoteada, derretida, diría, con los contornos difusos de todo lo que se derrite pero no termina de transformarse en otra cosa y no puede ser más que lo mismo en un derrumbe congelado antes de licuarse del todo. Desde esa caída que no cae, desde esa suspensión escribe. Y escribe cosas como esta" (Cabezón Cámara 2014, 68).

5. Uno de los pertenecientes a la "incipiente hermandad" pregunta: “¿cómo está la compañera del sacrificio fundante?" (33), refiriéndose a la quemada que le da cohesión al grupo de resistencia. 
Esto del "nosotros" y los "nuestros" atañe al testigo y a la víctima, que ronda la novela desde un principio. Cabezón juega con toda la corriente del testimonio en Latinoamérica y el Caribe y lo contrapone a la lectura posmoderna (Derrida y Agamben, entre otros). La paradoja es que quien casi muere sobrevive, la bonza necesita otra cara y presta testimonio por su propia boca:

De todos modos, acá quería hablar de martirio. El mártir es el testigo según la etimología, que no garantiza nada pero dice lo que dice y dice que el mártir es quien vio todo hasta el final, pero en el final no hay nada apenas la propia muerte y de eso no hay testimonios, el mártir no puede hablar más que con sus pobres restos, a lo sumo algo dirá cuando le hagan una autopsia o, si es mucho después, vía carbón 14. (76)

Pero la pregunta sería si para ser mártir, ¿no se necesita una comunidad? No son víctimas quienes mueren solos, sino que se es víctima de algo superior a nosotros. Creo que esto es lo que subrayan estos textos, el acto de victimación se convierte en la performance donde la protagonista es manipulada por un ente activo (los medios periodísticos) o los artísticos (igualmente deformadores). La protagonista parece tener conciencia intermitente de su situación, porque carece de motivos reales de resistencia. Su relato atañe a lo que es "debido" respecto a los sobrevivientes, pero incluso ella no lo es, sino como impostación, pese a haber sido el "origen” mismo de la acción: ella es la víctima que se asume como testigo en el relato que otro narra de ella. No hay origen, aunque haya que empezar por un punto (como ella dice en un momento). El comienzo de este personaje cuya resistencia no lo es, es un efecto de la merca, confundiéndose el principio del "yo" y del "nosotros" que constituye esta instalación: "yo estuve ahí, pero todo esto me lo contaron después" (14). El Modelo de esta instalación y performance que eventualmente es exhibido en la Bienal de Venecia es La Salada, un espacio de mercadería falsificada en las afueras de Buenos Aires, que se menciona fugaz, pero expresamente en el texto. Produce un "mercado" la performance, y es manipulable por los medios masivos, pero sobre todo, su circuito productivo se fundamenta en la simulación. La protagonista es su vivo ejemplo, la víctima típica a partir de la cual se sacraliza un espacio que la convierte en heroína: "yo solo les trabajé de víctima todo el día" $(37,60)$. Así como la Brenda (en la Berenguer de Naciste pintada) utiliza como espejo un charco, esta mujer se contempla en "la superficie 
convexa de los escudos militares" y le fascina el brillo azul de sus uniformes. Nos hallamos en la "sociedad del espectáculo", mas aquí se le superpone una cronología del despojo que será ocupado sucesivamente por la santidad y la performance, recursos mediáticos de diversas eras.

¿Qué ocurre cuando este sujeto absolutamente manipulado por el otro (el de la sociedad del espectáculo) se afirma precisamente en su propia autodesposesión? Es decir, ¿cómo leer desde otro sitio la aventura desterritorializadora de Gaby en La negra rubia? En Disposession: the Performative in the Political, Judith Butler y Athena Athanasiou (2013) exploran las consecuencias de lo que llaman la socialización de la autopoiesis ("the sociality of self-poietics”). Al cuestionar el reconocimiento, fundado en la identidad que se crea individualmente, afirmando la soberanía del sujeto, Athanasiou afirma que lo necesario no es producir identidades toleradas o tolerantes mercantilmente reconocibles, sino la desestabilización del ideal regulador que constituye el horizonte de esa susceptibilidad (66). Y advierte Butler sobre los peligros de la autopoiesis en un espacio donde se arriesga la inteligibilidad, planteando así un problema de traducción cultural: "we might be understood to be involved in a mode of self-making or self-poiesis that involves risking intelligibility, posing a problem of cultural translation and living in a critical relation to the norms of the intelligible" (67). Propone entonces moverse a otros regímenes de socialidad no necesariamente normativos.

Esta lectura de la protagonista nos colocaría como lectores en la apertura misma de una narración donde es incierto lo que se propone, entre la "soberanía" de la autopoiesis y el abandono o la indiferencia ante la posibilidad de ser un producto de una comunidad $\mathrm{X}$ que nos construye. Athanasiou comenta que la autopoética o self-poietics "emerges as a performative occasion in an ongoing process of socially regulatory self-formation" (68), donde el yo se desposesiona de su posición soberana abriéndose a la alteridad. Porque la alteridad también está en trance de construirse conjuntamente con el sujeto, no es un ente terminado. En esta nouvelle, Gaby examina continuamente a quién se parece, presagiando lúdicamente el trasplante: Darth Vader, Eva Perón, Abramovic y otros. Butler y Athanasiou ven en el modelo espacio-temporal un problema que atañe a la soberanía que están disputando. En las tres novelas, las protagonistas se hallan en un fuera de sí (estado alterno, enfermedad, delirio, encarcelamiento, convalescencia) que les permite vislumbrar la posibilidad 
de ser otro u otra, habitan en una especie de zona fronteriza entre la vida y la muerte. Entonces, la pregunta consiste en discernir si en el texto de Cabezón cuestiona el disenso neoliberal cuyo emblema es la okupa o propone un personaje cuya autoconstrucción como "sacrificada" confluye con las necesidades de una comunidad en ella. ¿Contra qué horizonte de expectativas la relación de un yo con su comunidad se va forjando? No solo se hallan fuera de sí estos personajes, sino avizorando otros territorios, ajenos, ominosos, amenazantes, foráneos. Sobre ese mismo horizonte de lectura, podríamos preguntar quién es el personaje de Daniel en la novela de Schweblin y o el de Gaby en El romance de la negra rubia, y sobre todo a quién interpelan. El que dichos personajes se perfilen sobre un tercer mundo acosado y envenenado en la intangible frontera globalizadora también dice mucho sobre la luz que los ilumina o ciega. ¿̇Acaso también no queremos abandonar el síndrome de la victimación? No enfocar en la injuria sino en la opresión, dice Butler (87), lo que me parece acertado, aunque estimo que es desde la injuria al cuerpo propio, desde su especificidad, desde donde mejor se puede estremecer al prójimo.

De otro lado, ambas novelas describen regímenes biopolíticos que de alguna manera comprometen el sentido de la identidad y se arrojan hacia lo trans: el trasgénico, la trasmigración, la transformación, el trasplante de rostro. En un pasaje, dice Gaby:

A veces creo que no caigo, que cuando muera será por proceso de ascensión, un poco como a la Virgen me arrebatará el muy alto y me caeré para arriba: seré un caso de inversión del centro de gravedad. Soy un caso de inversión: nací negra y me hice rubia, nací mujer y me armé de tremenda envergadura envidia de mucho macho y agua en la boca de tantos y de tanta boca loca. Me cogí a medio país, y también eso es poder. (35-6)

Entonces, desde la precariedad material de sus propios cuerpos (quemada, trans, híbrida, moribunda, envenenada) se reclama un mundo que habitar socialmente. La definición más breve de "performativity" en Butler es la siguiente: "performativity names that unauthorized exercise of a right to existence that propels the precarious into political life"; (the performative emerges precisely as the specific power of the precarious - unauthorized by existing legal regimes, abandoned by the law itself- to demand the end to their precarity" (101; 121, énfasis suplido). Y responde 
Athanasiou: "ask what might be made, politically, of such unauthorized, precarious exercises that seek to combat their own precarity" (101; énfasis suplido). La protagonista es un digno ejemplo de doble-agencia (Massiello 2003) unido ello a una necesidad de cuestionar e interpelar la sociedad en la que vive, manejadas las armas del poder interpretativo (Franco 1993) por una mujer. Lo que torna incierto su avatar o recorrido son las diversas máscaras asumidas, hasta el punto de hacer indistinto lo que su transformación plantea y aspira, políticamente hablando.

Es en su relación potencial con el otro que quiero cerrar este ensayo, incluso cuando en este caso se trata de una institución, de donde surge una escritura superlegitimada. En el "libro-documental" de Eltit, Puño y letra (2005), hay un texto que ostenta los signos de un discurso objetivo donde se escenifica un caso de violencia política. El implicado principal es el Estado pinochetista, y desde ahí Eltit reconfigura la materialidad del suceso apelando a nuestra imaginación abstracta, a la detallada evaluación de un pliego judicial. Citar la palabra mediante alegatos, testimonios e interrogatorios adquiere en este contexto una fuerza inusitada. Ese distanciamiento procura en los lectores una actitud, un gesto, una reflexión sobre los condicionamientos de nuestra lectura frente a la institución literaria, quien a su vez dicta un cierto tipo de escritura. Este "orden del discurso" que elabora Eltit suscita una reflexión sobre la violencia política ejercida por el Estado.

¿Cómo reacciona el lector ante un texto así? ¿Qué es la prueba, un testimonio, un alegato, un interrogatorio, una conclusión? ¿No constituyen todas estas piezas sueltas una intención narrativa? ¿Cómo se representa literariamente la violencia política a través de la transcripción de un caso judicial? En Puño y letra, asistimos a la exposición de unos documentos públicos puestos aquí en circulación general, descolocados del escenario jurídico donde usualmente adquieren su significado como parte del descubrimiento de prueba para comprobar la fidelidad con que se recuerda o la credibilidad del testigo. La conversión, mediante mera trasposición, de un documento público jurídico en un texto novelístico reduplica su significado, pues usualmente dichos documentos públicos, pese al nombre, se confinan al consumo exclusivo y especializado de los juristas. En este texto, un documento público como el testimonio judicial o la exposición oral de los abogados, adquiere otro aura al descontextualizarse y ubicarse dentro de una "novela", y su significado se altera al convertir el espacio 
real en un dispositivo estético, consistente en colocar en escena un fragmento documental. Ese captar el "progreso" específico del texto no es crucial para la lectura más ingenua del escrito, por lo que me pregunto si el lenguaje técnico, así como la acumulación de detalles solo pertinentes en un sentido jurídico podría promover un cierto sentido de "indignación" o "impaciencia" en la lectura convencional que orienta las expectativas de un lector lego. Si el grueso de la novela es esa larga cita extraída directamente del expediente judicial, entonces, ¿qué función desempeña reiterar mediante la extensa cita el lenguaje "neutro" de los juristas?

Son notables en estos textos los mecanismos de traducción, el desplazamiento de un texto judicial a una nouvelle, por ejemplo, y la posibilidad de que una testigo que hace visible su victimación por parte de una comunidad pueda exhibir descarnadamente su proceso. Asumirse como testigo es la forma que halla para asumirse como "una más" en la comunidad del agravio. Tampoco la protagonista en la nouvelle de Schweblin logra comprender lo que ocurre y somos nosotros como lectores quienes a partir de otros momentos de la narración logramos reconstruir el cuadro completo. No hay reclamo de verdad respecto a lo narrado, pues los documentos hablan por ellos mismos, pero mediante el encuadre previo y final, la autora cuestiona la institución judicial, prestigiada por la sacralidad simbólica de la que está investida, de su espacio de influencia, socavándola desde un principio y arrogándose simultáneamente el papel de testigo y juez de esta. Puede decirse que secuestra para su texto los documentos judiciales, colocándolos en un contexto diverso donde esgrime la palabra clave de la subjetividad criminal, la "alevosía", y pone en entredicho la efectividad de la pena. En ese sentido, se ha apropiado del poder interpretativo para torcer el rumbo de lo exclusivamente jurídico. Eltit toma como protagonista a la institución judicial misma, así como su lenguaje burocrático, y problematiza lo que esta institución puede hacer, que es poco, como puntualiza indirectamente a lo largo del texto. Si bien la autora irrumpe ensayísticamente, enmarcando valorativamente toda la acción, gesto característico del género testimonial (Vera León 2002), la conclusión o interpretación del gesto autorial reposa en nosotros, a quienes coloca en la posición de jueces éticos del acto. Si como dice Badiou,

6. Aquí y en lo que sigue remito a mi ensayo sobre la novela de Eltit, "Juzgar un juicio o las roturas de lo que se cose con afán (Puño y Letra, de Diamela Eltit)". 
la justicia debe definirse afirmativamente y consiste en el reconocimiento en la víctima de su espíritu, así como de su cuerpo, diría que esta obra es un ajusticiamiento, donde la espectadora comparece como "una más" del pueblo chileno, hace el reclamo respecto a la insuficiencia de la escena jurídica y se consolida como actuante, burlando el rol pasivo de la víctima. Es, como dice Badiou que es la justicia: "pasar de la condición de víctima a la condición de alguien que está de pie” $(2007,25)$.

Todos estos textos nos emplazan necesariamente para que respondamos, dado el límite que constituyen respecto al habla. Son textos dichos al borde de la muerte, al borde de lo que no puede decir otro que se asigna desde el texto mismo como testigo de la multiplicidad de signos que puede suscitar su interpretación. Son también, en ese sentido, textos que comentan oblicuamente la inteligibilidad, sobre si es posible entenderlos también, desde las redes del afecto y el trance ético. Por un lado entonces, las réplicas o resistencias a lo que es propio o la propiedad, la posibilidad de un disfrute diverso (el usufructo) que depende de la posesión pasajera y que en estos casos opera apalabrándose. Recordemos a ese efecto que es, en primer lugar, mediante el acto de habla que estas mujeres ocupan el espacio de la ciudad, del prostíbulo, del campo envenenado, incluso de la cárcel; y, en segundo lugar, por el compromiso del cuerpo en cuanto materialidad activa para expresar su visibilidad. Entonces, la desposesión vis a vis la soberanía que otorga la palabra a quienes la agencian es siempre un nódulo a desentrañar sobre la marcha. La desposesión está permanentemente relacionada con un aspecto que parecería negativo, pero en la medida en que pueda resignificarse de modo que el centro del cambio no emane necesariamente de un sujeto, sino de un entramado de sujetos diversos y diversas subjetividades comprometidas con la apertura, se convierte en un campo de posibilidades. Así también, el énfasis en la diferencia existente entre la habilitación de la cosa que provee la posesión ejercida por varios, en contraposición al concepto de propiedad, emblemático del uso restringido por el propietario.

El concepto de precariedad se liga necesariamente al tipo de vida conducida por algunos sujetos, carentes de territorio y visibilidad, aunque no deja de ser un recurso o estrategia de resistencia en algunos casos. Podría decirse que este es el lado radiante de la desposesión, en la medida en que el sujeto se torna permeable al mundo. Esa disponibilidad asume su rostro más oscuro cuando se torna violenta, en tanto no es producto 
de la disponibilidad del sujeto sino de la imposición de otro. El acto de nombrar, si bien es potencialmente político, también resulta estigmatizante. Nombrar es ya estar en el mundo, sea porque somos nombrados o nos nombramos o pedimos que nos renombren. Como señala Butler, ¿qué formas asume el nombrar cuando trata de deshacer el estatus soberano de aquel o aquella a quien nombra? $(2013,137)$. Esas formas las conocemos. Lo que quizá sea más difícil es afirmar el estatus soberano de alguien a quien ya sabemos es fácil nombrar y desnombrar, dada su invisibilidad y menoscabo, porque carece de poder para hacerse escuchar. Más allá del ejercicio descriptivo que adoptamos (las formas que asume el nombrar), habría que examinar las posibilidades de cuestionar ese lugar asignado por el nombre que desnombra. Apalabrarse es una de esas formas. Prometer, representar, autonombrarse, escribir la lengua materna y, en el acto, postular alternativas, lo cual sería un encuentro con la verdad. El acontecimiento (que dura un instante) llega, después del cual todo debe converger hacia un proceso. Ese acontecimiento, según Badiou (2002), nombra "el vacío", así como "lo desconocido de la situación”, a la que hay que serle fiel para lograr el encuentro con la "ética de la verdad". La fidelidad a dicho evento consistiría en dejarnos aprehender por lo desconocido que nos sorprende, emplazarnos en un proceso de verdad que trasciende la ley, que destruye el statu quo y nos quiebra, nos toma en ese encuentro. Quizá estas novelas aspiran a decirlo desde la marginalidad de dichas hablas y lugares. Entonces, la violencia que se registra o documenta aquí no es sufrida, sino evocada por las mujeres que la reduplican y subvierten para su provecho. *:

\section{Lista de referencias}

Badiou, Alain. 2002. Ethics. An Essay on the Understanding of Evil. Tr. Peter Hallward. London: Verso.

—. 2007. "La idea de justicia". En Justicia, filosofía y literatura, editado por Silvana Carozzi, 19-37. Rosario: Homo Sapiens ediciones.

Berenguer, Carmen. 1999. Naciste pintada. Santiago de Chile: Cuarto Propio.

Butler, Judith, y Athena Athanasiou. 2013. Dispossession: the Performative in the Political. Cambridge: Polity Press.

Cabezón Cámara, Gabriela. 2014. Romance de la negra rubia. Buenos Aires: Eterna Cadencia. 
Cárcamo Huechante, Luis. 2016. "La ciudad neoliberal y un habla rebelde: isomorfismos y voceos en Huellas de siglo de Carmen Berenguer". En Cuerpos y Hablas disidentes en la poesía de Carmen Berenguer, editado por Juan Pablo Sutherland, 59-83. Santiago de Chile: Piso Diez Ediciones.

Cresswell, Tim. 2004. Place: A Short Introduction. Malden, MA: Blackwell.

Eltit, Diamela. 2005. Puño y letra. Juicio oral. Barcelona: Seix Barral.

Franco, Jean. 1993 [1989]. Las conspiradoras. La representación de la mujer en México. Ciudad de México: Fondo de Cultura Económica / El Colegio de México.

-.2013. Cruel Modernity. Duke: Duke University Press.

Irigaray, Luce. 1985 [1974]. Speculum of the Other Woman. Traducción de Gillian C. Gill. Ithaca: Cornell UP.

—. 1985 [1977]. This Sex Which is Not One. Traducción de Catherine Porter y Carolyn Burke. Ithaca: Cornell UP.

Leal, Francisco. 2007. “Aparecen sombras criminales. Arte y política en la obra de Carmen Berenguer." Revista de Crítica literaria latinoamericana. Año 33, n. ${ }^{\circ}$ 65: 51-61.

Lizama, Jaime. 2016. "Hacia una reescritura de lo femenino". En Cuerpos y Hablas disidentes en la poesía de Carmen Berenguer, editado por Juan Pablo Sutherland, 41-55. Santiago de Chile: Piso Diez Ediciones.

Massey, Doreen. 1994. "The Political Space of Localities Studies”. En Space, Place, \& Gender. Minneapolis: University of Minnesota Press.

Massiello, Francine. 2003. "Women as Double Agents in History". En Narrativa femenina en América Latina, 59-72. Madrid: Iberoamericana Vervuert.

- 2016. "Ritmo y presencia: 'Las damas vuelven'”. En Cuerpos y Hablas disidentes en la poesía de Carmen Berenguer, editado por Juan Pablo Sutherland, 27-39. Santiago de Chile: Piso Diez Ediciones.

Sotomayor-Miletti, Áurea María. 2012. "Juzgar un juicio o las roturas de lo que se cose con afán (Puño y Letra, de Diamela Eltit)". Revista Iberoamericana (University of Pittsburgh). Octubre-diciembre. Vol. LXXVIII, n. ${ }^{\circ}$ 241: 1011-24.

Vera León, Antonio. 2002. "Hacer hablar: la transcripción testimonial”. En La voz del otro: testimonio, subalternidad y verdad narrativa, $2{ }^{a}{ }^{\mathrm{a}}$ ed., editado por John Beverley y Hugo Achúgar, 195-213. Ciudad de Guatemala: Universidad Rafael Landívar.

Schweblin, Samanta. 2014. Distancia de rescate. Buenos Aires: Random House Mondadori.

—. 2015. Pájaros en la boca. Buenos Aires: Random House Mondadori. 